\title{
Laparoscopic peritoneal lavage: our experience and review of the literature
}

\author{
Amilcare Parisi ${ }^{1}$, Alessandro Gemini ${ }^{1}$, Jacopo Desiderio ${ }^{1}$, Adolfo Petrina ${ }^{2}$, Stefano Trastulli ${ }^{1}$, Veronica Grassi ${ }^{1}$, \\ Marco Sani ${ }^{1}$, Daniele Pironi ${ }^{3}$, Alberto Santoro ${ }^{3}$ \\ ${ }^{1}$ Department of Digestive Surgery, St. Mary's Hospital, University of Perugia, Terni, Italy \\ ${ }^{2}$ Department of General Surgery, St. Maria della Misericordia's Hospital, University of Perugia, Perugia, Italy \\ ${ }^{3}$ Department of Surgical Sciences, Sapienza University of Rome, Rome, Italy
}

Videosurgery Miniinv 2016; 11 (2): 83-87

DOI: $10.5114 /$ wiitm.2016.60236

\begin{abstract}
Introduction: Over the years various therapeutic techniques for diverticulitis have been developed. Laparoscopic peritoneal lavage (LPL) appears to be a safe and useful treatment, and it could be an effective alternative to colonic resection in emergency surgery.

Aim: This prospective observational study aims to assess the safety and benefits of laparoscopic peritoneal lavage in perforated sigmoid diverticulitis.

Material and methods: We surgically treated 70 patients urgently for complicated sigmoid diverticulitis. Thirty-two (45.7\%) patients underwent resection of the sigmoid colon and creation of a colostomy (Hartmann technique); 21 (30\%) patients underwent peritoneal laparoscopic lavage; 4 (5.7\%) patients underwent colostomy by the Mikulicz technique; and the remaining 13 (18.6\%) patients underwent resection of the sigmoid colon and creation of a colorectal anastomosis with a protective ileostomy.

Results: The 66 patients examined were divided into 3 groups: 32 patients were treated with urgent surgery according to the Hartmann procedure; 13 patients were treated with resection and colorectal anastomosis; 21 patients were treated urgently with laparoscopic peritoneal lavage. We had no intraoperative complications. The overall mortality was $4.3 \%$ (3 patients). In the LPL group the morbidity rate was $33.3 \%$.

Conclusions: Currently it cannot be said that LPL is better in terms of mortality and morbidity than colonic resection. These data may, however, be proven wrong by greater attention in the selection of patients to undergo laparoscopic peritoneal lavage.
\end{abstract}

Key words: laparoscopic peritoneal lavage, Hartmann's procedure, diverticular disease, colon resection, urgency.

\section{Introduction}

Diverticulosis of the colon is a common condition in Western countries [1]. The prevalence is largely age-dependent, and it is uncommon in people under the age of 40 , where the prevalence is estimated at approximately $5 \%$, increasing to $65 \%$ in those aged 65 or more [2]. Diverticular disease consists of di- verticulosis, diverticulitis and diverticular bleeding. Diverticulosis is the presence of diverticula within the colon; diverticulitis is the inflammation of a diverticulum [3]. Diverticulitis can range from simple forms characterized by modest inflammation to complicated forms characterized by pericolic abscesses, perforations and fecal peritonitis [1, 4]. Abdominal sepsis related to complicated diverticulitis

\section{Address for correspondence}

Alessandro Gemini MD, Department of Digestive Surgery, St. Mary's Hospital, University of Perugia, 05100 Terni, Italy,

phone: +3907442051, e-mail: alessandrogemini@hotmail.com 
is defined according to Hinchey's classification, with abscess formation scored as Hinchey I or II, purulent peritonitis as Hinchey III, and fecal peritonitis as Hinchey IV [5]. The management is dictated by the stage of the disease at the time of its presentation and by the response of the patient to the initiated treatment $[6,7]$. Over the years different therapeutic techniques for diverticulitis have been developed. The treatment of choice in non-peritonitis forms can be conservative medical treatment (Hinchey I) or percutaneous drainage (Hinchey II). On the other hand, in more severe forms (Hinchey III and IV), surgical resection (Hartmann procedure vs. colon resection and anastomosis with or without stoma) is still considered the treatment of choice by most surgeons [8-10]. Several authors report that the latter two procedures are burdened by high rates of mortality and morbidity [11-13]. The advent of laparoscopic surgery in the treatment of abdominal emergencies and in colon surgery has led surgeons to use a minimally invasive approach for the treatment of complicated diverticulitis, with a growing number of studies and amount of experience. Laparoscopic peritoneal lavage (LPL), described for the first time in 1996 by O'Sullivan [14], appears to be a safe and useful treatment, and it could be an effective alternative to colonic resection in emergency surgery [ 10 , $15,16]$. It is interesting to study the rate of incidence of recurrent diverticulitis in patients undergoing LPL. It is also important to decide when to perform a colonic resection electively after LPL [17].

\section{Aim}

This prospective observational study aims to assess the safety and benefits of laparoscopic peritoneal lavage in perforated sigmoid diverticulitis.

\section{Material and methods}

In the period between January 2007 and December 2014, we treated surgically 70 patients urgently for complicated sigmoid diverticulitis. From the analysis of these cases it appeared that 32 (45.7\%) patients underwent resection of the sigmoid colon and creation of a colostomy (Hartmann technique); 21 (30\%) patients underwent peritoneal laparoscopic lavage; 4 (5.7\%) patients underwent a "double-barrel" colostomy (Mikulicz's technique); and the remaining $13(18.6 \%)$ patients underwent resection of the sigmoid colon and creation of a colorectal anas- tomosis with protective ileostomy. In this paper we will refer to the cases treated in emergency for complicated acute diverticulitis, and we will compare the results obtained in the patients who underwent resection-anastomosis at one time with ileostomy protection with those of the patients treated with the Hartmann technique and with those of the patients submitted only to peritoneal wash (in total 66 patients). We excluded from our analysis patients treated with Mikulicz's technique due to the small number of cases. All the patients examined in this study underwent preoperative clinical examination and blood tests, abdominal ultrasound and abdominal CT with contrast medium. We performed an LPL in patients who were hemodynamically stable, where the pre-operative tests showed covered perforated diverticula (that are perforated diverticula not free in the abdomen) or localized peritonitis or in the cases where it was not possible to exclude a complicated diverticulitis. In these cases it was up to the operator to decide between open or laparoscopic surgery, and it was still up to him to perform Hartmann's technique or a resection with anastomosis. When we performed the LPL, we adopted the same technique described by other authors [14, 15, 18-21]. Normally we used three trocars (two $10-12 \mathrm{~mm}$ and one $5 \mathrm{~mm}$ ). We began with a thorough evaluation of the peritoneal cavity in order to assess the feasibility and safety of the procedure. In patients with many adhesions we did not perform any adhesiolysis; if any perforation was detected, resection was mandatory so the patients were excluded from the LPL group. Then we carried out intra-peritoneal lavage with saline solution without antibiotics; we did not use a predetermined amount of saline solution: the irrigation continued until we obtained a clear fluid. At the end of the procedure one or two drains were placed and unstable patients were sent to intensive care. After the surgery, the patients were treated with broad-spectrum antibiotics with fasting from 5 to 7 days. All patients who were subjected to LPL at 8-12 weeks were then subjected to colonoscopy or virtual colon computed tomography (CT) scan.

\section{Results}

The characteristics of the enrolled patients are summarized in Table I. The mean age of the patients was $66.92 \pm 11.03$ years. The median body mass index (BMI) was $26.7 \pm 4.72 \mathrm{~kg} / \mathrm{m}^{2}$. The median fol- 
Table I. Characteristics of enrolled patients

\begin{tabular}{|lc|}
\hline Characteristics & Result \\
\hline Total & 70 \\
\hline Gender (male/female), $n$ & $28 / 42$ \\
\hline Age $\left[\right.$ years] ${ }^{*}$ & $66.92 \pm 11.03$ \\
\hline BMI $\left[\mathrm{kg} / \mathrm{m}^{2}\right]^{*}$ & $26.7 \pm 4.72$ \\
\hline ASA score, $n(\%):$ & $19(27.1)$ \\
\hline I & $38(54.3)$ \\
\hline II & $9(12.9)$ \\
\hline III & $4(5.7)$ \\
\hline IV & $42 / 28$ \\
\hline Comorbidity $(Y / N)$ & $65(92.9)$ \\
\hline Hinchey stage, $n(\%):$ & $5(7.1)$ \\
\hline III & $13(18.6)$ \\
\hline IV & $32(45.7)$ \\
\hline Type of procedure, $n(\%):$ & $21(30.0)$ \\
\hline Direct anastomosis & $4(5.7)$ \\
\hline Hartmann & \\
\hline Peritoneal lavage & \\
\hline Mikulicz & \\
\hline Values are expressed as mean $\pm S D$. & \\
\hline
\end{tabular}

low-up was $30.45 \pm 25.94$ months. According to the American Society of Anesthesiologists (ASA) classification, 19 (27.1\%) patients were ASA I, 38 (54.3\%) patients were ASA II, 9 (12.9\%) patients were ASA III, and $4(5.7 \%)$ patients were ASA IV. The 66 patients examined were divided into 3 groups: 32 patients (27 Hinchey III and 5 Hinchey IV) were treated with urgent surgery according to the Hartmann procedure; 13 patients (Hinchey III) were treated with resection and colorectal anastomosis (in all cases a protective ileostomy was also performed); 21 patients (Hinchey III) were treated urgently with laparoscopic peritoneal lavage. We had no intraoperative complications.

Table II. Follow-up details

\begin{tabular}{|lc|}
\hline Parameter & Result \\
\hline Mean follow-up [months] & $30.45 \pm 25.94$ \\
\hline Overall mortality, $n(\%)$ & $4(5.7)$ \\
\hline $\begin{array}{l}\text { Disease recurrence after peritoneal } \\
\text { lavage, } n(\%)\end{array}$ & $7(33.3)$ \\
\hline $\begin{array}{l}\text { Elective surgery after peritoneal } \\
\text { lavage, } n \text { (\%) }\end{array}$ & $6(28.57)$ \\
\hline $\begin{array}{l}\text { Urgent surgery after peritoneal lavage } \\
\text { (Hartmann procedure), } n(\%)\end{array}$ & $4(19.04)$ \\
\hline
\end{tabular}

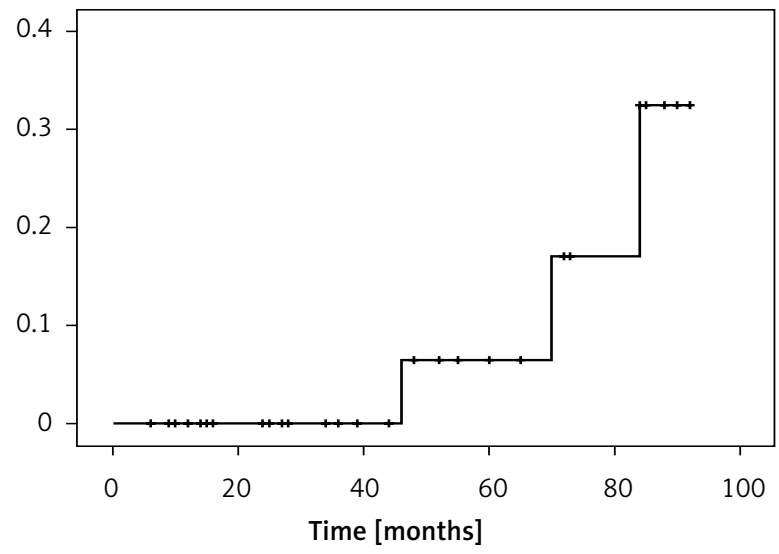

Figure 1. Cumulative risk of mortality after Hartmann procedure

The overall mortality was $4.3 \%$ (3 patients). Deaths were found only in the group of patients undergoing the Hartmann procedure (Figure 1), 3 of 32 (9.4\%) patients. All these patients were ASA 4 and had Hinchey IV disease. The morbidity rate in patients undergoing Hartmann's procedure was 3.1\% (just 1 patient re-operated for bowel obstruction). In the LPL group the morbidity rate was 33.3\%.

Analyzing the follow-up data in patients undergoing LPL (Table II), we found that the procedure was successful in 14 (66.7\%) patients while 7 (33.3\%) patients required re-hospitalization for sigmoid diverticulitis (Figure 2). Elective laparoscopic sigmoid resection, with creation of a colorectal anastomosis without protective ileostomy, was performed in 6 (42.85\%) of the 14 patients for whom LPL had been successful. The reason for surgery was the presence, at the post-operative investigations, of important

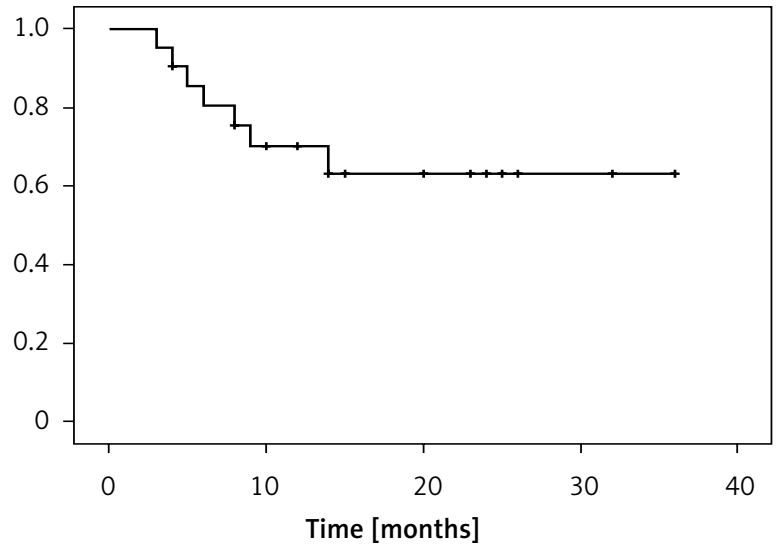

Figure 2. Disease free survival after peritoneal lavage 
signs of inflammation of the colon with a high risk of recurrence of the disease or the presence of stenosis. In the group of patients who required re-hospitalization for sigmoid diverticulitis (33.3\%), 4 patients were treated urgently and underwent open surgery for resection of the sigmoid colon and creation of a colostomy (Hartmann's technique), while 3 patients underwent electively, after medical therapy, laparoscopic sigmoid resection with primary colonic anastomosis without protective ileostomy.

\section{Discussion}

Treatment for diverticulitis is constantly changing. The debate on what is the most appropriate treatment is particularly heated. Over the last twenty years it has gone from interventions with open surgery to minimally invasive interventions. It has shown that therapeutic treatment must be based on the state of the patient's disease, ranging from medicinal treatment to surgery depending on the Hinchey stage $[1,8,22]$. The debate focuses mainly on complicated forms. There is a controversy about what constitutes the ideal treatment of perforated diverticulitis. Basically two approaches have emerged over the years to treat this type of patient: resection of the inflamed and perforated colon with a colostomy (Hartmann's procedure), or resection with primary colonic anastomosis (with or without an ileostomy) $[4,13,23]$. Despite the progress in this field, these two methods have morbidity corresponding to $34-44 \%$ for Harman's procedure and 23-29\% for primary colonic anastomosis; the mortality rate is $15-19 \%$ for Hartmann's procedure and $9-20 \%$ for primary colonic anastomosis [12, 13, 17, 23]. The LPL generated interest in order to reduce morbidity and mortality related to these surgical techniques. Laparoscopic lavage for the management of perforated diverticulitis was originally described in eight patients with full resolution [14]. Later in 2008, Myers et al. published an article reporting a success rate of $95 \%$ in 92 patients undergoing LPL. The same article reported morbidity and mortality rates of 4 and $3 \%$, respectively [18]. The systematic review of Toorenvliet et al., published in 2010, including 231 patients undergoing LPL, showed success of the procedure in $95.4 \%$ of cases, with mortality of $1.7 \%$ and morbidity of $10.4 \%$ [11]. The review article of Afshar and Kurer [24] reported a morbidity rate of $18.9 \%$ and a mortality rate of $0.25 \%$. The results obtained in our series are similar to those of previous studies $[11,17$, 18, 24]. Our mortality rate, in patients undergoing LPL, was $0 \%$ and our morbidity rate was $33.3 \%$. The LPL was successful in $66.7 \%$ of cases. In 6 patients (42.5\% of all patients undergoing LPL) it allowed us to avoid a colostomy by performing a delayed primary anastomosis. According to another study, LPL could also be used as a bridge therapy to avoid a colostomy [10]. The randomized controlled trial DILALA [16] seems to confirm the feasibility and safety, in the short term, of laparoscopic lavage in Hinchey type III patients. The short-term results of this study [16] do not show differences in mortality or overall morbidity among patients undergoing LPL and those undergoing Hartmann's resection. Another randomized study compared laparoscopic lavage with sigmoidectomy: the LOLA group of the LADIES trial [25]. This trial was terminated earlier for safety reasons. In fact, the authors reported that LPL does not reduce morbidity and mortality compared to sigmoidectomy, although laparoscopic peritoneal lavage did result in a higher acute reintervention rate. In the article, however, it is emphasized that the highest rate of reinterventions does not cause higher mortality [25]. In the SCANDIV trial, which is consistent with the LOLA trial, the reoperation rate was higher in the LPL group (20.3\%) than in the resection group (5.7\%) [26]. In the study of the Scandiv Study Group, the authors note that LPL was not so effective as resection in eradicating the primary focus of infection. Our data are consistent with those of the above trial. They do not show a statistically significant reduction in mortality and morbidity of patients with LPL compared to those treated with colonic resection. However, some consideration should be made on the use of LPL. The most important consideration is that LPL must be reserved for carefully selected patients [27]. If there is a perforation, a resection must always be made (Hartmann vs. colon resection and anastomosis). The challenge is to identify patients without a perforation who could benefit from LPL and those with occult perforation where the LPL would fail. Laparoscopic peritoneal lavage also allows colonic resection to be avoided for those patients whose pre-operative examinations do not exclude a perforated diverticulitis. So LPL can improve the quality of life in selected patients, allowing them to overcome the acute phase of diverticulitis, and postponing the resection and colonic anastomosis. This will avoid subjecting these patients to a colostomy. 


\section{Conclusions}

Currently it cannot be said that LPL is better in terms of mortality and morbidity than colonic resection. Modern studies have rejected the initial expectations about LPL's superiority in relation to the other surgical techniques. These data may, however, be proven wrong by greater attention in the selection of patients to undergo laparoscopic peritoneal lavage. In addition, a parameter that should be considered in assessment of the advantages of $\mathrm{LPL}$ is the patient's quality of life. Anyway, at the moment, in no case may patients with colonic perforation be subjected to laparoscopic peritoneal lavage.

\section{Conflict of interest}

The authors declare no conflict of interest.

\section{References}

1. Cirocchi R, Farinella E, Trastulli S, et al. Elective sigmoid colectomy for diverticular disease. Laparoscopic vs open surgery: a systematic review. Colorectal Dis 2011; 14: 671-83.

2. Parks TG. Natural history of diverticular disease of the colon. Clin Gastroenterol 1975; 4: 53-69.

3. Murphy T, Hunt RH, Fried M, Krabshuis JH. Divertucular disease. WGO Practice guidelines. http://www.worldgastroenterology. org/guidelines/global-guidelines/diverticular-disease/diverticular-disease-english.

4. Krukowski ZH, Matheson NA. Emergency surgery for diverticular disease complicated by generalized and faecal peritonitis: a review. Br I Surg 1984; 71: 921-7.

5. Hinchey EJ, Schaal PG, Richards GK. Treatment of perforated diverticular disease of the colon. Adv Surg 1978; 12: 85-109.

6. Lockhart-Mummery JP. Late results of diverticulitis. Lancet 1938; 2: 1401-4.

7. Cirocchi R, Trastulli S, Desiderio J, et al. Treatment of Hinchey stage III-IV diverticulitis: a systematic review and meta-analysis. Int J Colorectal Dis 2013; 28: 447-57.

8. Wong WD, Wexner SD, Lowry A, et al. Practice parameters for the treatment of sigmoid diverticulitis - supporting documentation. The Standards Task Force. The American Society of CoIon and Rectal Surgeons. Dis Colon Rectum 2000; 43: 290-7.

9. Favuzza J, Friel JC, Kelly JJ, et al. Benefits of laparoscopic peritoneal lavage for complicated sigmoid diverticulitis. Int J Colorectal Dis 2009; 24: 797-801.

10. Cirocchi R, Trastulli S, Vettoretto N, et al. Laparoscopic peritoneal lavage: a definitive treatment for diverticular peritonitis or a "bridge" to elective laparoscopic sigmoidectomy? A systematic review. Medicine (Baltimore) 2015; 94: e334.

11. Toorenvliet BR, Swank H, Schoones JW, et al. Laparoscopic peritoneal lavage for perforated colonic diverticulitis: a systematic review. Colorectal Dis 2010; 12: 862-7.

12. Salem L, Flum DR. Primary anastomosis or Hartmann's procedure for patients with diverticular peritonitis? A systematic review. Dis Colon Rectum 2004; 47: 1953-64.
13. Constantinides VA, Tekkis PP, Athanasiou T, et al. Primary resection with anastomosis vs. Hartmann's procedure in non-elective surgery for acute colonic diverticulitis: a systematic review. Dis Colon Rectum 2006; 49: 966-81.

14. O’Sullivan GC, Murphy D, O’Brien MG, et al. Laparoscopic management of generalized peritonitis due to perforated colonic diverticula. Am J Surg 1996; 171: 432-4.

15. Swank HA, Mulder IM, Hoofwijk AG, et al. Early experience with laparoscopic lavage for perforated diverticulitis. Br J Surg 2013; 100: 704-10.

16. Angenete E, Thornell A, Burcharth J, et al. Laparoscopic lavage is feasible and safe for the treatment of perforated diverticulitis with purulent peritonitis: the first results from the randomized controlled trial DILALA. Ann Surg 2016; 263: 117-22.

17. Sorrentino M, Brizzolari M, Scarpa E, et al. Laparoscopic peritoneal lavage for perforated colonic diverticulitis: a definitive treatment? Retrospective analysis of 63 cases. Tech Coloproctol 2015; 19: 105-10.

18. Myers E, Hurley M, O’Sullivan GC, et al. Laparoscopic peritoneal lavage for generalized peritonitis due to perforated diverticulitis. Br J Surg 2008; 95: 97-101.

19. Liang S, Russek K, Franklin ME Jr. Damage control strategy for the management of perforated diverticulitis with generalized peritonitis: laparoscopic lavage and drainage versus laparoscopic Hartmann's procedure. Surg Endosc 2012; 26: 2835-42.

20. Toorenvliet BR, Swank H, Schoones JW, et al. Laparoscopic peritoneal lavage for perforated colonic diverticulitis: a systematic review. Colorectal Dis 2010; 12: 862-7.

21. White SI, Frenkiel B, Martin PJ. A ten-year audit of perforated sigmoid diverticulitis: highlighting the outcomes of laparoscopic lavage. Dis Colon Rectum 2010; 53: 1537-41.

22. Kohler L, Sauerland S, Neugebauer E. Diagnosis and treatment of diverticular disease: results of a consensus development conference. The Scientific Committee of the European Association for Endoscopic Surgery. Surg Endosc 1999; 13: 430-6.

23. Vermeulen J, Lange JF. Treatment of perforated diverticulitis with generalized peritonitis: past, present, and future. World J Surg 2010; 34: 587-93.

24. Afshar S, Kurer MA. Laparoscopic peritoneal lavage for perforated sigmoid diverticulitis. Colorectal Dis 2012; 14: 135-42.

25. Vennix S, Musters GD, Mulder IM, et al.; Ladies Trial Colloborators. Laparoscopic peritoneal lavage or sigmoidectomy for perforated diverticulitis with purulent peritonitis: a multicentre, parallel-group, randomised, open-label trial. Lancet 2015; 386: 1269-77.

26. Schultz JK, Yaqub S, Wallon C, et al.; SCANDIV Study Group. Laparoscopic lavage vs primary resection for acute perforated diverticulitis: the SCANDIV Randomized Clinical Trial. JAMA 2015; 314: 1364-75.

27. Rossi GL, Mentz R, Bertone S, et al. Laparoscopic peritoneal lavage for Hinchey III diverticulitis: is it as effective as it is applicable? Dis Colon Rectum 2014; 57: 1384-90.

Received: 29.03.2016, accepted: 28.04.2016. 